\title{
Analysis of a quarter car suspension system based on nonlinear shock absorber damping models
}

\author{
V. M. Barethiye, G. Pohit and A. Mitra \\ Department of Mechanical Engineering, \\ Jadavpur University, Kolkata 700032, India \\ Phone: +91 332414 6890; Fax: ++91 3324146890 \\ Email: vmbarethiye@ vjti.org.in, gpohit@gmail.com, samik893@gmail.com
}

\begin{abstract}
Shock absorber is a critical element of vehicle suspension system with nonlinear characteristics. In the present work, performance of vehicle characteristics was analysed by quarter car model to study the effect of shock absorber, on the basis of linear and nonlinear damping characteristics. In addition to linear and piecewise linear, polynomial damping characteristics were considered to address the nonlinear aspect of damping characteristics. The linear and nonlinear properties of the shock absorber were incorporated in a two degree of freedom quarter car suspension system. The modelling and simulation is carried out in Adams view environment and Matlab/Simulink. A bump road profile was used to excite the quarter car suspension models. The polynomial shock absorber model was validated using experimental data taken from established literature. Simulation was undertaken to study the dynamic performance in terms of sprung mass acceleration, body displacement, suspension deflection and unsprung mass acceleration. Experimental hysteresis characteristics data, taken from established literature, were also modelled in Adams view environment and the simulated results were used for validation purpose. The suspension system response incorporating shock absorber represented by nonlinear model, hysteresis model and piece wise linear model were provided in the result section for comparison. It was observed from quantitative comparisons that the RMS values for body acceleration and body displacement of the polynomial model matched fairly well with the results of experimental hysteresis response. It was concluded that in order to study the dynamic characteristics of the vehicle accurately, nonlinear behaviour of the damper is required to be captured properly. Therefore, the proposed polynomial shock absorber model can be a better option for vehicle dynamic analysis as compared to the complex hysteresis model.
\end{abstract}

Keywords: Shock absorber; linear; piecewise linear; polynomial; quarter car; Adams view; Simulink.

\section{INTRODUCTION}

The suspension system is a mechanism that physically separates the car body from the car wheel. The main function of the vehicle suspension system is to minimise the vertical acceleration transmitted to the passenger from the ground, providing better ride comfort [1-3]. Due to the decades of research work in the field, various types of suspension system are in use at present. However, work is going on to develop better quality of suspension systems. Hence, the dynamic simulation and analysis of different types of suspension 
systems are still interesting and important research topics. The shock absorber is one of the most important parts of vehicle suspension system, which has an effect on ride characteristics. It is also used to control the transient behaviour of the sprung and unsprung masses of the vehicle $[4,5]$. It is one of the most complex part of the suspension system because of its non-linear and complex behaviour. In fact, the damping force of the dampers behaves with unsymmetrical nonlinear hysteresis loop [6-9]. Hence, a good representation of the shock absorber's behaviour and its analysis is important in vehicle dynamic studies. Extensive research on the suspension system has been carried out since 1977 [6-15]. Wallaschek [11] stated that if the properties of a shock absorber are identified using the experimental technique, then the equivalent linear model can be used for the dynamics of shock absorber. Reybrouck [12] developed a physical damper model on semi-empirical coefficients. However, he did not consider the effect of physical parameters on damper characteristics. Duym [13] claimed that instead of linear model, two or three slope models of shock absorbers can be a better representation of damper.

Experimental analysis and modelling of shock absorber (car and motorcycle) have been carried out by many researchers [6-9, 16-23]. Liu and Zhang [6, 7] carried out an experiment on twin tube hydraulic shock absorber of a passenger's car and obtained the damping force-velocity curves which are characterised to be hysteretic loop. The authors also developed a virtual prototype of the hydraulic shock absorber in the Adams environment. A Calvo et al. [8] analysed the influence of the shock absorber models on the dynamic behaviour of vehicle. Raj et al. [22] developed a passive nonlinear damper for automobiles, which improves the ride characteristics which the damping velocity changes with stroke. Improvement over the ride and handling characteristics of suspension system has a wide scope. Therefore, researchers use the application of software tools like Simulink and Adams view for analysis, and simulation of vehicle suspension system [24-30]. Adams view with quarter car model has been used to represent McPherson suspension system [2]. Kim and Ro [28] used parameter identification method to consider the effect of suspension linkages. The authors also developed a complex suspension model using Adams view to show the relationship between suspension kinematic structure and identified parameter. Blundell [29] modelled the rear suspension system by using Adams view and showed the effect of rubber bush compliance on vehicle suspension movement. By using quarter car model, several researchers have carried out investigations on vehicle performance analysis [5, 31-34] using hydraulic shock absorber or MR fluid damper [35]. The full car modelling and analysis [36-43] had been carried out by some of the researchers. Kim and Ro [36] presented 7 DOF full car model by using identified equivalent parameters of kinematic structure and showed an important effect on roll related properties, whereas, Darus and Sam [38] used a linear active suspension model to check the performance of a full car model. Cui and Kurfess [41] stated that for larger shock velocities, the nonlinear effect of shock absorber must be considered. The author used a hybrid shock absorber model in full car model using system identification technique.

Simpler models such as linear and piecewise linear models are inadequate to capture the behaviour of the shock absorber and hence, the performance of a vehicle. Therefore, it is essential to develop a model of the shock absorber that can capture nonlinear hysteresis characteristics of the damper. It has been observed from the literature review that much work has already been carried out using linear and piecewise linear damper models. However, the force-velocity characteristic of a damper is inherently non-linear. Therefore, in the present paper, shock absorber force-velocity characteristics were modelled by a polynomial function in addition to a linear, piecewise linear model. In 
addition, hysteresis behaviour of a damper obtained from actual experimental data [6] was also simulated in Adams environment. The simulation of a two-degree of freedom quarter car model was carried out by using Matlab/Simulink and dynamic response had been validated against a realistic model developed in Adams environment. Subsequently, the responses of the car quarter models under different road excitation were observed. The objective of the paper is to determine the efficacy of the proposed linear and nonlinear shock absorber models to simulate dynamic responses of the vehicle based on different road profile inputs.

\section{METHODS AND MATERIALS}

\section{Shock Absorber Damping Models}

The shock absorber, being one of the most important elements in a vehicle suspension system, is an interesting and popular domain of research as already witnessed from the literature review. The force-velocity characteristic having hysteresis in behaviour, obtained from the experimental data [6] provides the basis for assuming the damping characteristic present in the system. The experimental hysteresis curve is fitted with three different curves, namely, linear, piecewise linear and polynomial, to obtain a mathematical equation for the force-velocity relation. Later the damping characteristic of the shock absorber system is fed to a simple quarter car system to predict the effect of considering the linear as well as nonlinear damper. Modelling and simulation was carried out by using Adams view and Matlab/Simulink. The experimental force-velocity characteristic [6] is also directly used in Adams environment for quarter car simulation as an indication of a realistic vehicle behaviour.

\section{Linear Viscous Damping Model}

Linear model is the simplest model used in the present simulation-based analysis. It considers linear damping force vs. velocity relation with constant damping coefficient. A linear fitting is performed on experimental force-velocity plot shown in Figure 1 and the damping coefficient for linear behaviour is identified.

\section{Piecewise Linear Model}

In order to provide the damping in the suspension system, the shock absorber dissipates energy in the compression stroke (jounce) and extension stroke (bounce) whenever a vehicle moved over a bump on the road. The positive force shown on the graph (see Figure 1) is for the extension stroke (which is also known as rebound stroke) and the negative force represents the compression stroke. The force in the rebound region is more than the force in the compression region [8, 44]. Assuming a piecewise bilinear shock absorber behaviour [8], Eq. (1) and (2) are considered to represent the force-velocity relation for compression and rebound regions.

For rebound

$$
f=\left\{\begin{array}{lr}
c_{r 1} v, & 0 m / s \leq v<0.2 m / s \\
c_{r 2} v, & v \geq 0.2 m / s
\end{array}\right.
$$

Here $c_{r 1}$ and $c_{r 2}$ are damping coefficients for rebound regions.

For compression 


$$
f=\left\{\begin{array}{lr}
c_{c 1} v, & -0.2 \mathrm{~m} / \mathrm{s} \leq v<0 \mathrm{~m} / \mathrm{s} \\
c_{c 2} v, & v>-0.2 \mathrm{~m} / \mathrm{s}
\end{array}\right.
$$

Here, $c_{c 1}$ and $c_{c 2}$ are damping coefficients for compression regions.

The values of the damping coefficients are obtained by fitting the force-velocity curve shown in Figure 1. They are mentioned in Table 1.

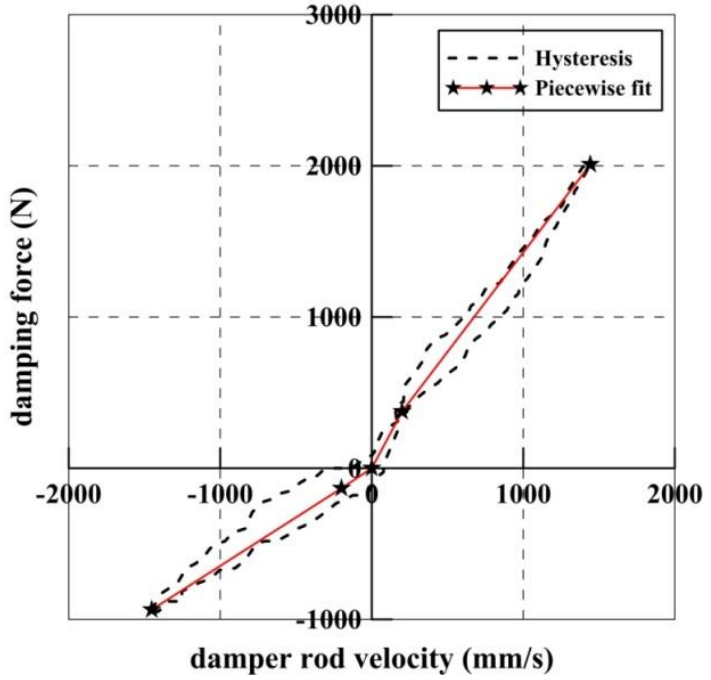

(a)

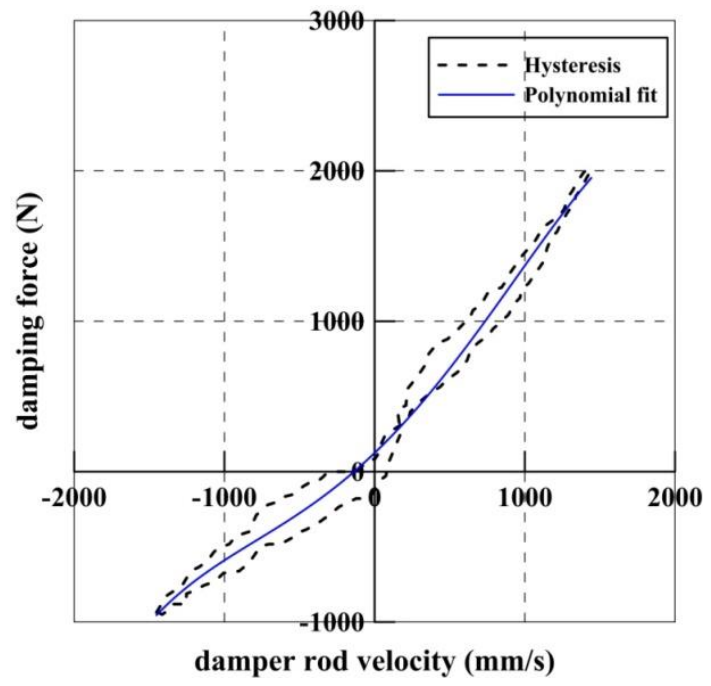

(b)

Figure 1. Damping models (a) Piecewise linear; (b) Polynomial.

Table 1. Quarter car suspension parameters.

\begin{tabular}{lll}
\hline Param- & Description (unit) & Numerical value \\
\hline$m_{s}$ & Sprung mass $\left(k_{g}\right)$ & 476 \\
$m_{u}$ & Unsprung mass $\left(k_{g}\right)$ & 50 \\
$k_{s}$ & Suspension stiffness $(K N / m)$ & 26.4 \\
$k_{t}$ & Tyre stiffness $(K N / m)$ & 220 \\
$c_{s}$ & Linear damping coefficient $(N s / m)$ & 3500 \\
$c_{r 1}$ & Damping coefficient for rebound $(N s / m)$ & 2775 \\
$c_{r 2}$ & Damping coefficient for rebound $(N s / m)$ & 1875 \\
& Damping coefficient for compression & $(v \geq 0.2 \mathrm{~m} / \mathrm{s})$ \\
$c_{c 1}$ & $(N s / m)$ & $(-0.2 \mathrm{~m} / \mathrm{s} \leq \mathrm{v}<0 \mathrm{~m} / \mathrm{s}$ \\
& Damping coefficient for compression & 665 \\
$c_{c 2}$ & $(N s / m)$ & $(v>-0.2 \mathrm{~m} / \mathrm{s})$ \\
\hline
\end{tabular}

\section{Polynomial model}

In order to capture the nonlinear properties of the shock absorber, a polynomial model is proposed. A general form for a polynomial of order $j$ is considered as shown below.

$$
f(x)=a_{0}+a_{1} x+a_{2} x^{2}+a_{3} x^{3}+\ldots \ldots . .+a_{j} x^{j}
$$



as follows:

In the polynomial model, the damping force-velocity characteristic is expressed

$$
f=\sum_{i=0}^{n} a_{i} v^{i}
$$

Here $f$ is the damper force, $v$ is the piston velocity and $a_{i} \mathrm{~s}$ are the coeffieceints for variable $v$ in the polynomial. In the present work, the order of the polynomial, $\mathrm{n}$ is chosen as 4 . The coefficients of the polynomial shown in Eq. 5 are determined by fitting the curve of Figure 1. The matching of the proposed piecewise linear model and polynomial model with the force-velocity curve of the actual damper [6] characteristics are illustrated in Figure 1.

$$
f=124.5+956.7 v+342.7 v^{2}+23.14 v^{3}-77.14 v^{4}
$$

\section{Quarter Car Model}

In the present work, the quarter car model is represented by a two-degree of freedom spring-mass-damper system as shown in Figure 2. The mass of the vehicle is represented by sprung mass $m_{s}$ and the mass of the wheel and associated components is represented by unsprung mass $m_{u}$. The vertical motions of the two masses are described by the displacement variables $x_{s}$ and $x_{u}$ for sprung and unsprung mass, respectively. The road excitation disturbance is given by $x_{r}$. In the quarter-car model, the suspension is located in between the sprung mass and un-sprung mass. The spring of the suspension system has stiffness $k_{s}$, whereas, the damper characterises the shock absorber having its forcevelocity relation is based on the models described in the preceding section. Stiffness of the tyre is represented by a second spring connected to the unsprung mass, having coefficient $k_{t}$. Both the springs used in the system are assumed to be linear in nature with constant spring coefficients. It should be mentioned here that tire damping is considered to be negligible as compared to the system damping.

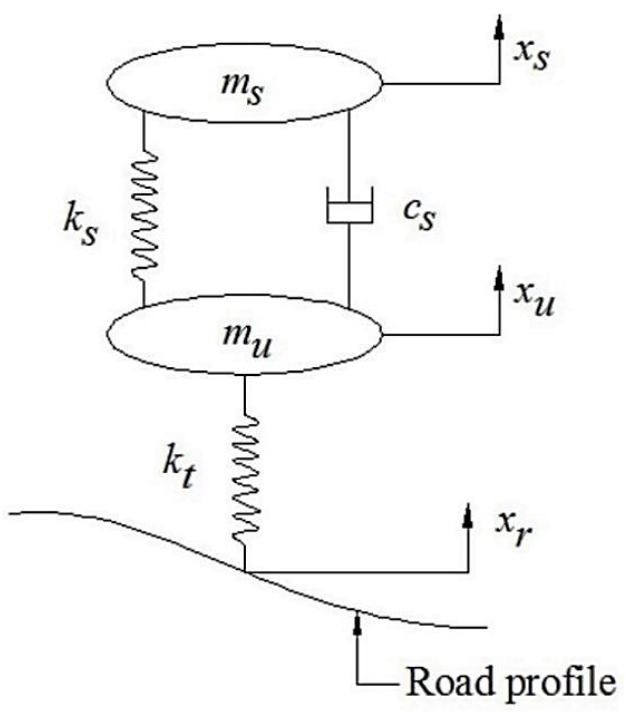

Figure 2. Quarter car model. 
The quarter car model is simulated in Simulink platform to study the vehicle response with specific road disturbance as input. While modelling the system, previously discussed damping models (such as linear, piecewise linear and polynomial) are incorporated as the shock absorber properties. For the validation of Simulink results, Multi Body Dynamics (MBD) simulation software and Adams view, are used. In case of Adams, linear and piecewise linear damping characteristics are utilised to generate the vehicle performance results. The experimental hysteresis data [6] for damping property are also fed to the Adams environment to obtain a realistic idea view of the vehicle's performance.

The equations of motion of the masses $m_{s}$ and $m_{u}$ are given as

$$
\begin{gathered}
m_{s} \ddot{x}_{s}+k_{s}\left(x_{s}-x_{u}\right)+f=0 \\
m_{u} \ddot{x}_{u}-k_{s}\left(x_{s}-x_{u}\right)-k_{t}\left(x_{r}-x_{u}\right)-f=0
\end{gathered}
$$

Here $f$ is damper force, which is described by the three different shock absorber models as mentioned in the previous section. The expressions for the damper force are also mentioned with respect to the quarter car system shown in Figure 2.

$$
\begin{array}{cr}
f=c_{s}\left(\dot{x}_{s}-\dot{x}_{u}\right) \\
f=c_{r 1}\left(\dot{x}_{s}-\dot{x}_{u}\right) & 0 m / s \leq v<0.2 m / s \\
f=c_{r 2}\left(\dot{x}_{s}-\dot{x}_{u}\right) & v \geq 0.2 \mathrm{~m} / \mathrm{s} \\
f=c_{c 1}\left(\dot{x}_{s}-\dot{x}_{u}\right) & -0.2 \mathrm{~m} / \mathrm{s} \leq v<0 \mathrm{~m} / \mathrm{s} \\
f=c_{c 2}\left(\dot{x}_{s}-\dot{x}_{u}\right) & v>-0.2 \mathrm{~m} / \mathrm{s} \\
\mathrm{f}=124.5+956.7\left(\dot{\mathrm{x}}_{\mathrm{s}}-\dot{\mathrm{x}}_{\mathrm{u}}\right)+342.7\left(\dot{\mathrm{x}}_{\mathrm{s}}-\dot{\mathrm{x}}_{\mathrm{u}}\right)^{2} \\
+23.14\left(\dot{\mathrm{x}}_{\mathrm{s}}-\dot{\mathrm{x}}_{\mathrm{u}}\right)^{3}-77.14\left(\dot{\mathrm{x}}_{\mathrm{s}}-\dot{\mathrm{x}}_{\mathrm{u}}\right)^{4}
\end{array}
$$

The vehicle parameters used for the quarter car simulation are listed in Table 1 . The values of masses and spring constants were taken from Calvo et al. [8], whereas the values of damping coefficients for force-velocity properties of shock absorber corresponding to linear and piecewise linear models were obtained by fitting appropriate curves to the experimental data as mentioned in the previous section.

\section{Road Profile}

In the simulation study, the road profile $\left(x_{r}\right)$ needs to be expressed in terms of mathematical equations and the road input to excite the quarter car models is set in the form shown in below Eq. (11). The following road disturbance profile [45-47] is used.

$$
x_{r}=\left\{\begin{array}{c}
\frac{a(1-\cos (8 \pi t))}{2} \text { if } 0.50 \leq t \leq 0.75 \text { and } 3.00 \leq t \leq 3.25 \\
0 \text { otherwise }
\end{array}\right.
$$

where, $a$ denotes maximum bump amplitude which is set to be $11 \mathrm{~cm}$ for $0.5 \leq \mathrm{t} \leq 0.75$ and $5.5 \mathrm{~cm}$ for $3.00 \leq \mathrm{t} \leq 3.25$. The resulting road profile due to bump amplitude is shown in furnished in Figure 3. 


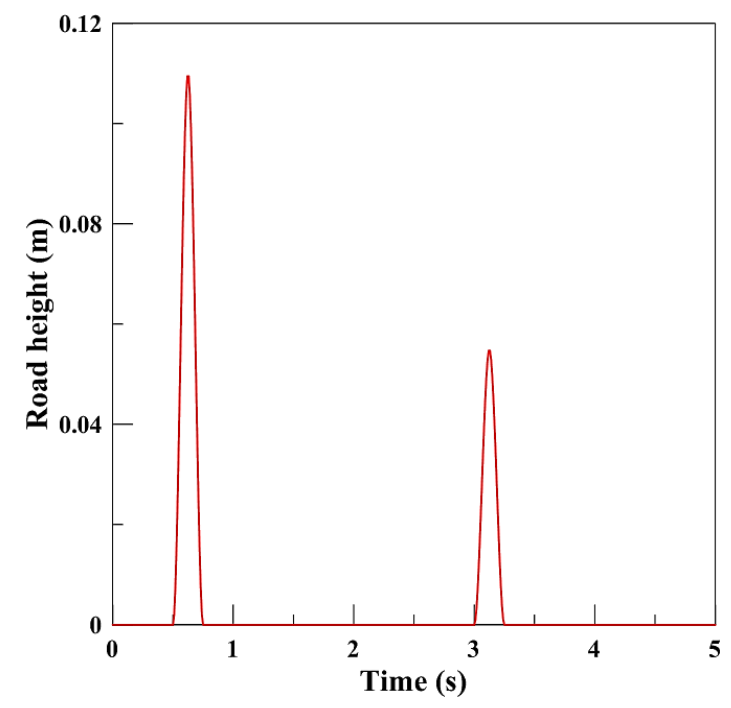

Figure 3. Road Profile created in Simulink corresponding to bump amplitude input of $11 \mathrm{~cm}$ for $0.5 \leq \mathrm{t} \leq 0.75$ and $5.5 \mathrm{~cm}$ for $3.00 \leq \mathrm{t} \leq 3.25$.

\section{Modelling of Quarter Car System}

The quarter car system described here has been modelled with Simulink software as discussed in the following paragraphs. Modelling of the quarter car system with linear, piecewise linear and polynomial characteristics of the shock absorber is accomplished by utilising different Simulink blocks and subsystem blocks. Figure 4 represents the subsystem block developed to simulate quarter car model with piecewise linear damping characteristic. The velocity conditions governing the characteristics of the piecewise linear shock absorber are implemented under the 'interpreted Matlab function' block. Similar subsystem blocks are also developed for linear and the polynomial behaviours of the shock absorber. The combined quarter car system Simulink block with linear, piecewise linear and polynomial subsystems is shown in Figure 5. The simulation is carried out to plot vehicle performance for body acceleration, body displacement, suspension deflection and unsprung mass acceleration.

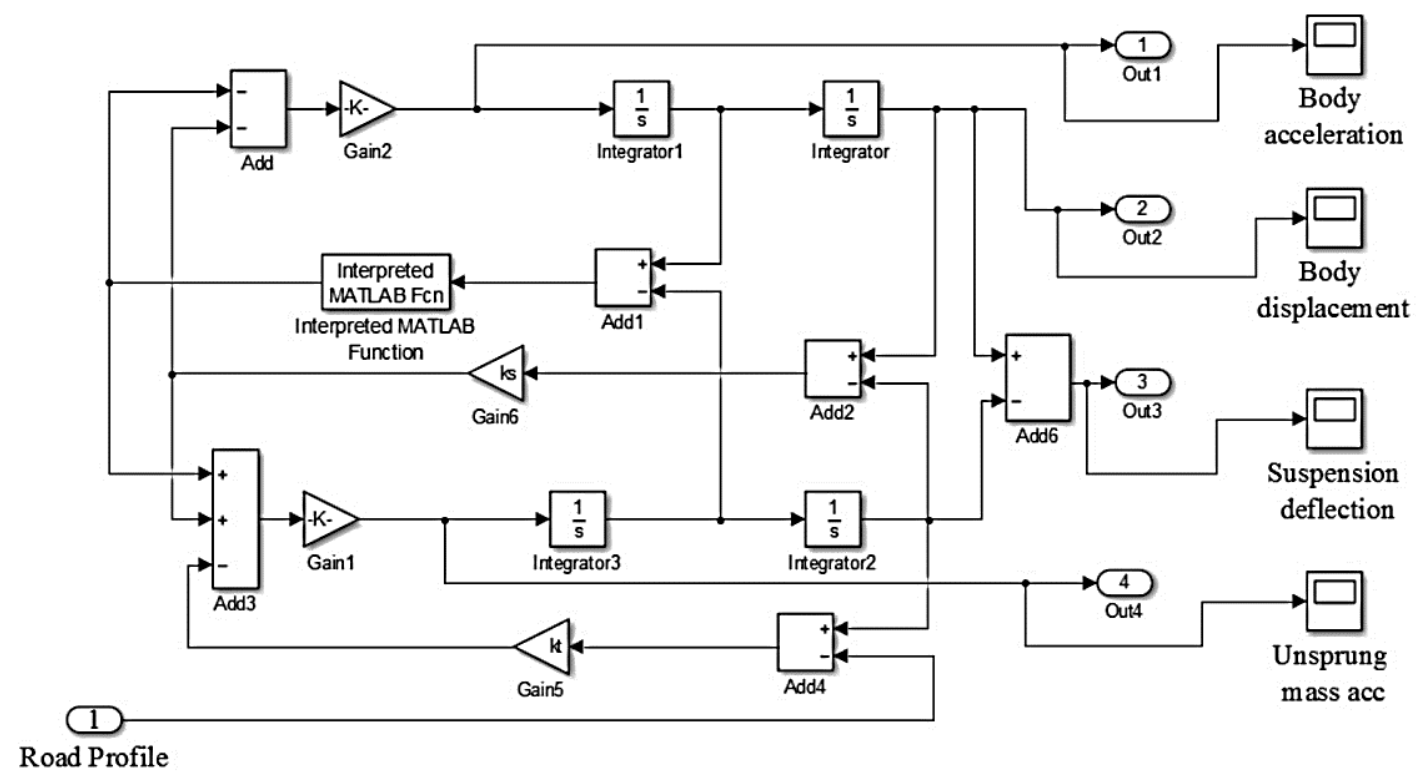

Figure 4. Quarter car model with piecewise linear characteristic of shock absorber. 


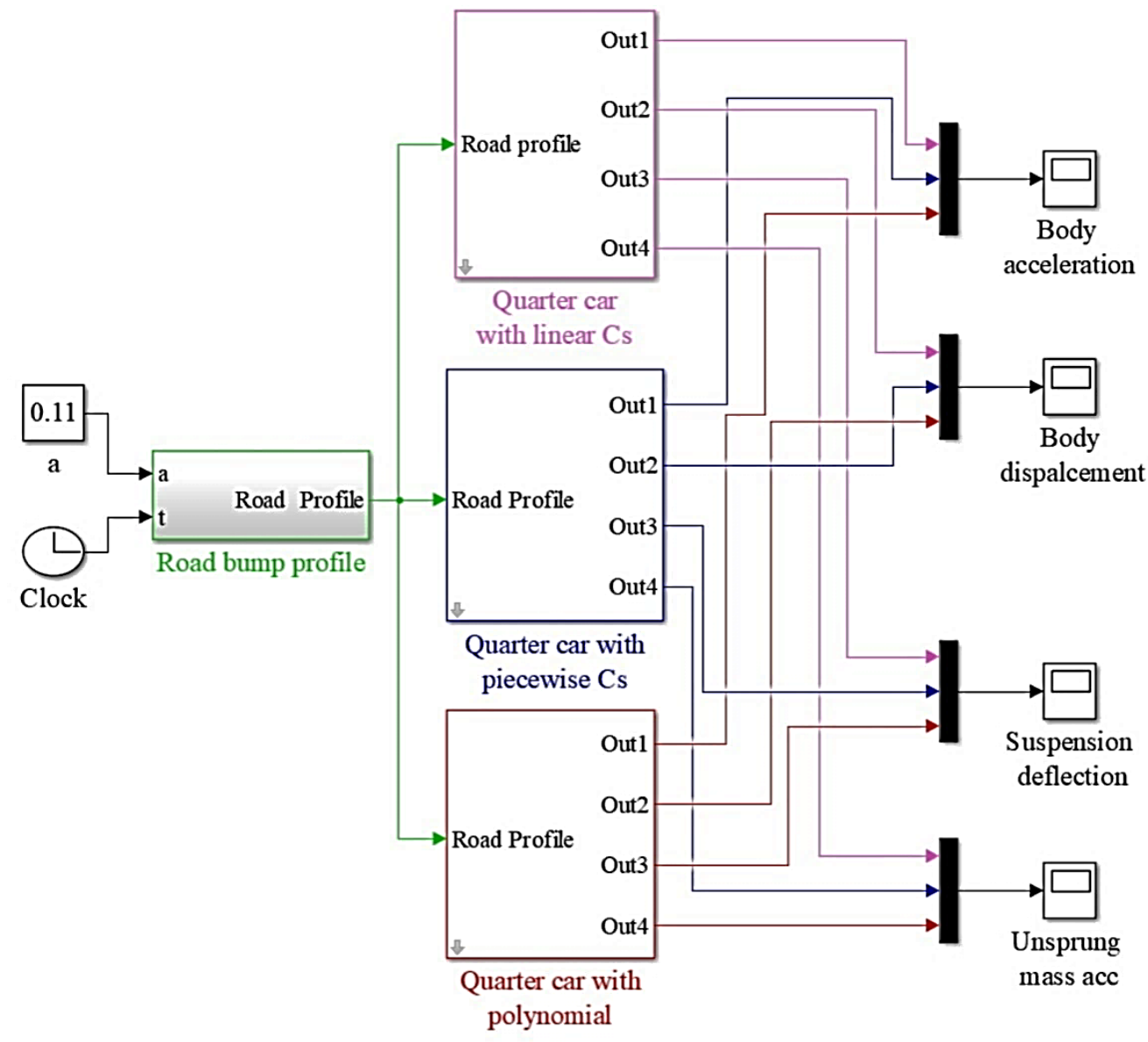

Figure 5. Combined quarter car modelling with linear, piecewise linear and polynomial characteristics of shock absorber.

The Adams view, a multi body dynamic analysis software, provides realistic simulation of complicated dynamic systems and hence is a convenient tool for model validation [26-27, 36]. In the present paper, quarter car system with linear, piecewise linear and experimental hysteresis damping characteristics of the shock absorber is modelled using Adams view environment and subsequently appropriate results are generated to compare them with the results of Simulink analysis. A quarter car suspension system was modelled as a spring-mass system as shown in Figure 6. The motion restrictions are imposed in such a way that the masses are only capable of vertical motion. The sprung mass and unsprung mass was connected by a spring-damper assembly and their motion is guided by translational joints. For linear damping characteristics, the spring-damper assembly is supplied with constant spring stiffness (due to consideration of linear spring) as well as a fixed value for damping coefficient $\left(C_{s}\right)$. Force-velocity characteristics of piecewise linear model and experimental hysteresis model are represented by using a SPLINE function. The base is also modelled as a translational joint for vertical deflection and it is connected to the unsprung mass through a linear spring. The road disturbance profile $\left(x_{r}\right)$ is given as STEP input function to the translational joint at the base and the motion is imposed on this joint in $\mathrm{Z}$ (vertical) direction. The composition of the function $\left(x_{r}\right)$ is given below. 
$x_{r}=\operatorname{STEP}($ time $, 0.5,0.0,0.625,0.11)+\operatorname{STEP}($ time $, 0.625,0.0,0.75,-0.11)$

+ STEP (time, 3.0, 0.0, 3.125, 0.055) +STEP (time, 3.125, 0.0, 3.25, -0.055).

Plots for body/sprung mass acceleration, body displacement, suspension deflection and unsprung mass acceleration are obtained from Adams view simulation.

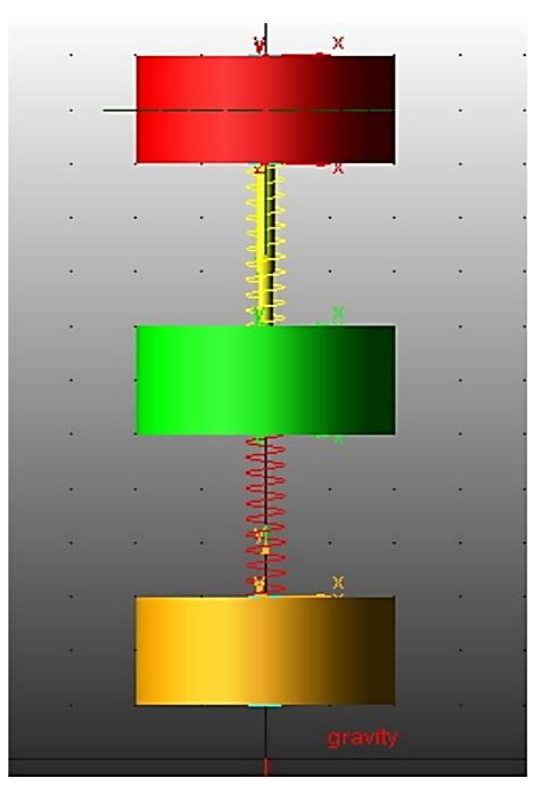

(a)

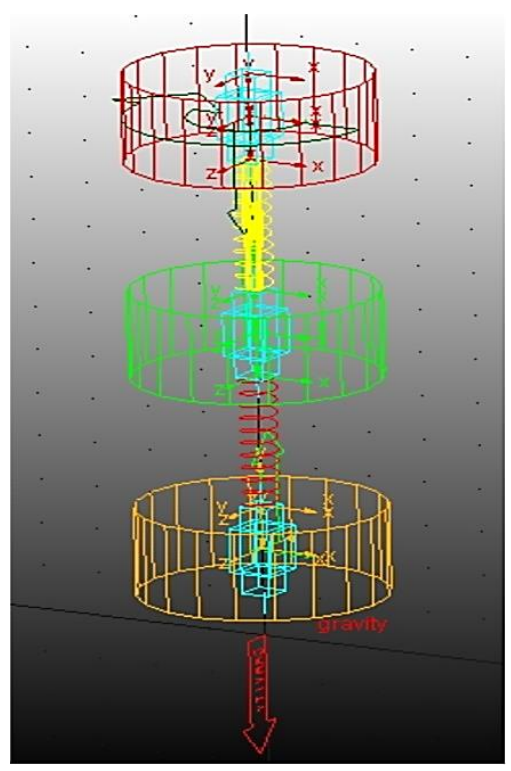

(b)

Figure 6. Quarter car model implemented in Adams view (a) two dimensional and (b) three dimensional view.

\section{RESULTS AND DISCUSSION}

The dynamic responses of the suspension system in the form of sprung and unsprumg mass acceleration were analysed due to specific road bump excitation. The simulations were carried out for linear, piecewise linear and polynomial damping properties of shock absorber by using Simulink software. Results corresponding to linear, piecewise linear and experimental damping characteristics were also generated in Adams view environment for comparison purpose and to establish the validity of the model. It needs to be mentioned here that to assess the dynamic behaviour of suspension system, sprung mass acceleration (body acceleration) and body displacement are the parameters mostly used as criteria which are related with passenger comfort [8-9, 27]. The quarter car and full car modelling simulations were done in the past by various researchers $[2,32,38,40$, 42] to consider a linear viscous damping model for the shock absorber. The present study incorporates piecewise linear and polynomial (nonlinear) damping characteristics into the modelling of quarter car suspension systems. Comparison of the simulated results from Simulink and Adams view is provided for linear and piecewise linear damping models in Figure 7 (a) and 7 (b). Each of these figures consists of four different parameter plots showing body acceleration, body displacement, suspension deflection and unsprung mass acceleration. It is obvious from the figures that there is good agreement between the two sets of results. 


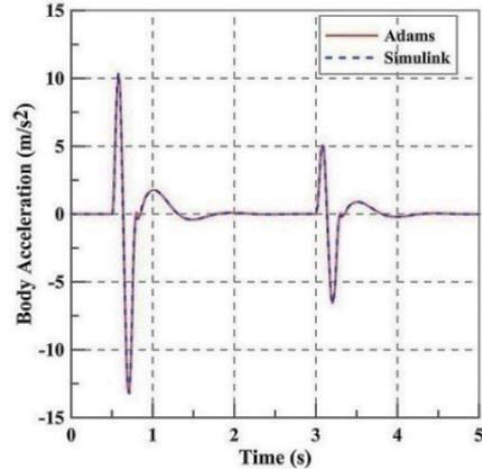

(i)

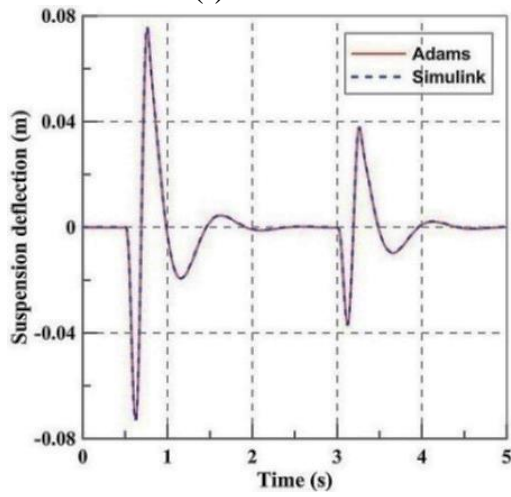

(iii)

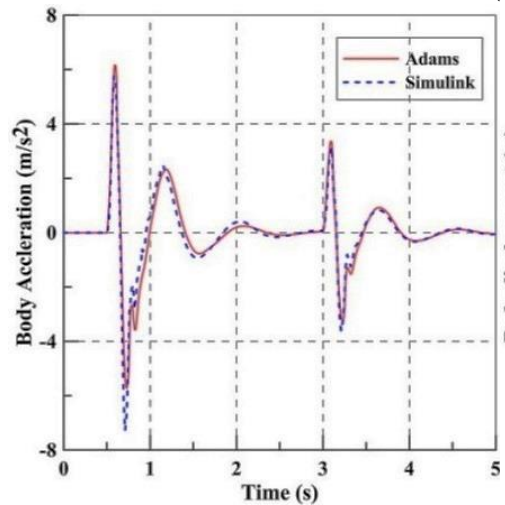

(i)

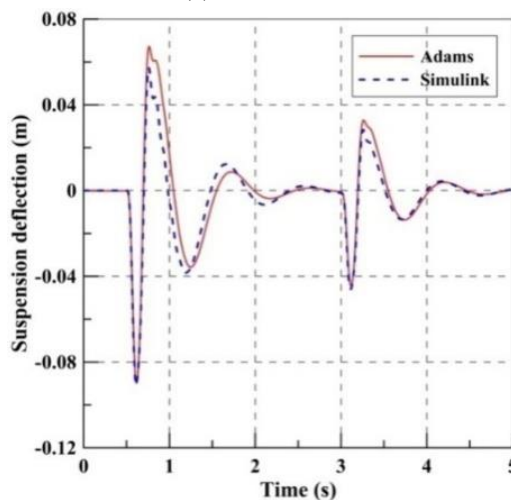

(iii)

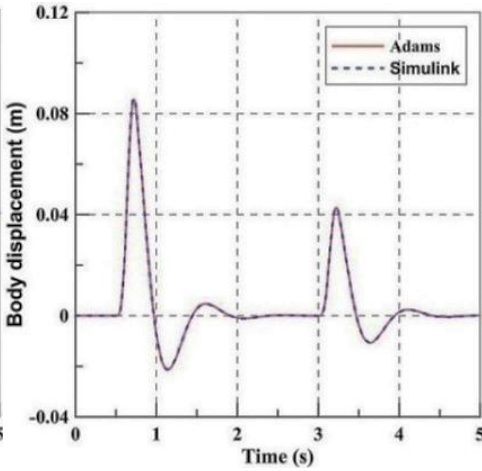

(ii)

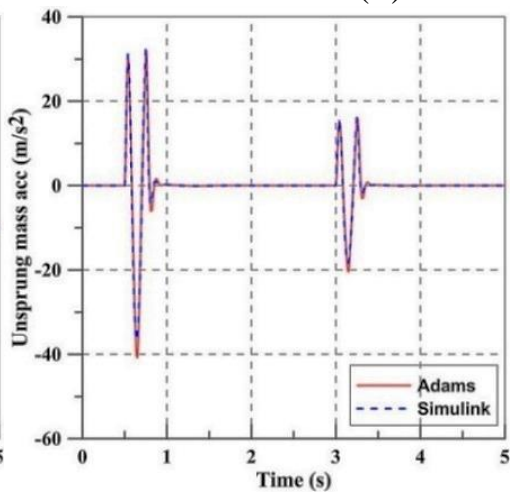

(iv)

(a)

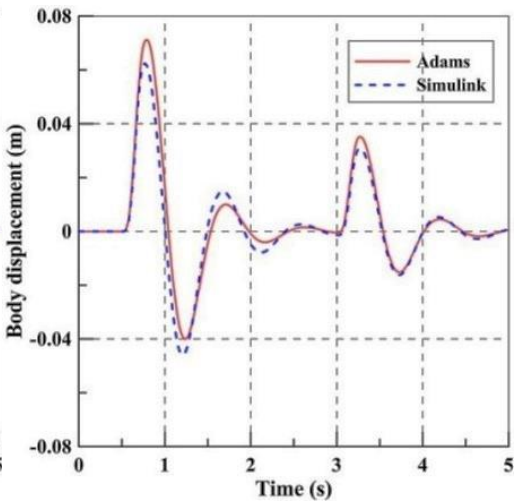

(ii)

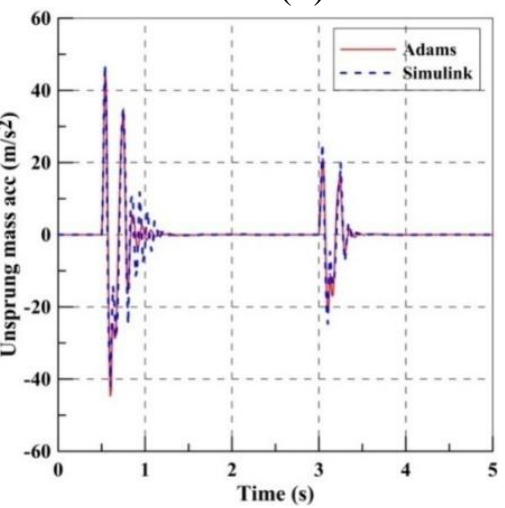

(iv)

(b)

Figure 7. Simulation results for (i) body acceleration (ii) body displacement (iii) suspension deflection (iv) unsprung mass acceleration for (a) linear and (b) piecewise linear damping properties. 
Comparative quantitative numerical values of peak amplitude of the quantities (body acceleration, body displacement, suspension deflection and unsprung mass acceleration) are shown in Table 2. It is evident from Figure 7 and Table 2 that piecewise linear shock absorber model gives lower amplitude for body acceleration as well as lower overshoot for body displacement. Suspension deflection of piecewise linear model is found to be lower even though amplitude is only slightly lower than the linear model. The two-slope or three-slope model of shock absorbers can be used instead of the linear model of shock absorber for better representation of nonlinear characteristics [13], of a damper. The linear model can only capture linear behaviour. However, most of the damper exhibit greater force in the extension region compared to compression region. When discrete type excitation occurs, such as a step or bump, the unsprung mass acceleration excitation is large as it is placed before the damper. Also, it means that the effect of different damping models is not exhibited in unsprung mass acceleration. Hence, the unsprung mass acceleration in both cases showed similar behaviour.

Table 2. Comparative quantitative numerical values of peak amplitude.

\begin{tabular}{lllll}
\hline \multirow{2}{*}{$\begin{array}{l}\text { Vehicle performance } \\
\text { characteristics }\end{array}$} & \multicolumn{2}{l}{ For linear damper } & $\begin{array}{l}\text { For piecewise linear } \\
\text { damper }\end{array}$ \\
\cline { 2 - 5 } & Simulink & Adams & Simulink & Adams \\
\hline Body acceleration $\left(\mathrm{m} / \mathrm{s}^{2}\right)$ & 10.55 & 9.07 & 5.74 & 6.33 \\
Body displacement $(\mathrm{m})$ & 0.0861 & 0.0676 & 0.0623 & 0.0602 \\
Suspension deflection $(\mathrm{m})$ & 0.0759 & 0.0808 & 0.0614 & 0.0768 \\
Unsprung mass acceleration $\left(\mathrm{m} / \mathrm{s}^{2}\right)$ & 30.81 & 31.88 & 47.06 & 43.85 \\
\hline
\end{tabular}

Figure 8 shows the Adams view results for body acceleration, body displacement, suspension deflection and unsprung mass acceleration corresponding to linear, piecewise linear and hysteresis (experimental) damping characteristics. In Figure 9, body acceleration, body displacement and suspension deflection are plotted against time corresponding to linear, piecewise linear and polynomial damping characteristic using Simulink. In order to have a comprehensive comparison of the three damping models for a realistic performance, the simulated results of the hysteresis curve was also included in the plots (see Figure 9). Table 3 shows the quantitative analysis of vehicle performances in terms of RMS and peak amplitude for damping models.

Table 3. Quantitative analysis of vehicle performances in terms of RMS and peak amplitude for damping models.

\begin{tabular}{lcccc}
\hline \multicolumn{1}{c}{ Parameter } & Linear & Piece-wise & Hysteresis & Polynomial \\
\hline Peak body acceleration, m/s $\mathrm{s}^{2}$ & 10.557 & 5.753 & 5.930 & 5.938 \\
Body acceleration (RMS), m/s & 2.838 & 1.664 & 1.987 & 1.827 \\
Peak body displacement, m & 0.0859 & 0.0577 & 0.0675 & 0.0676 \\
Body displacement (RMS), m & 0.0238 & 0.0198 & 0.0285 & 0.0263 \\
Peak suspension deflection, m & 0.0759 & 0.0573 & 0.0636 & 0.0636 \\
Suspension deflection (RMS), m & 0.0224 & 0.0234 & 0.0320 & 0.0296 \\
\hline
\end{tabular}




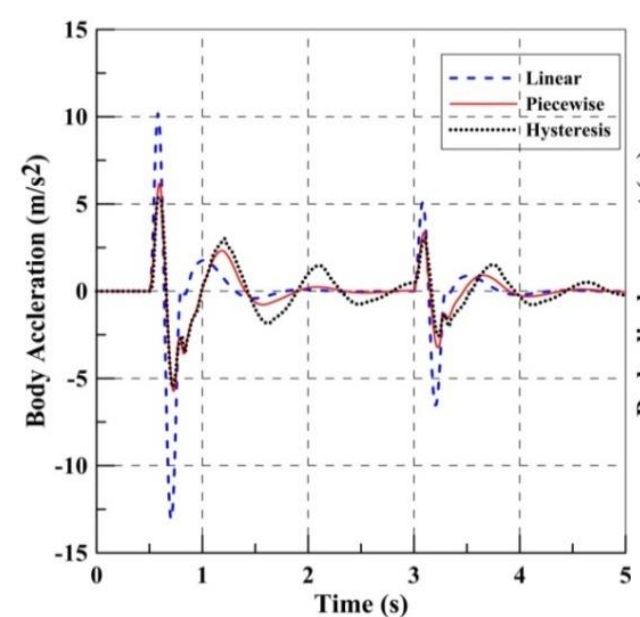

(a)

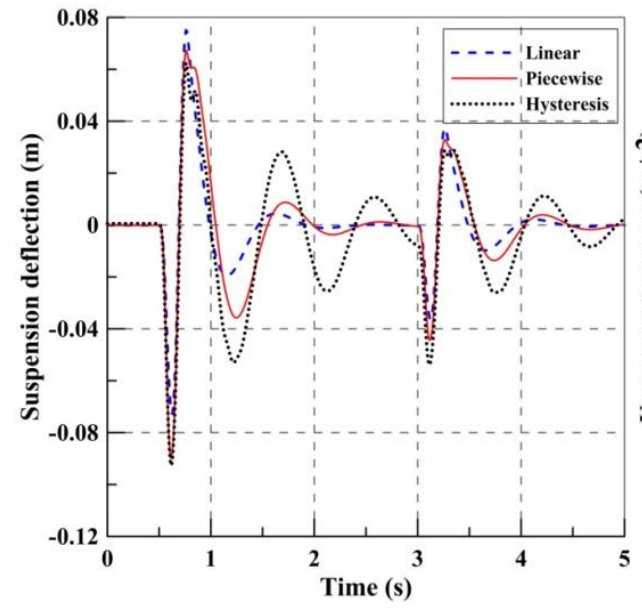

(c)

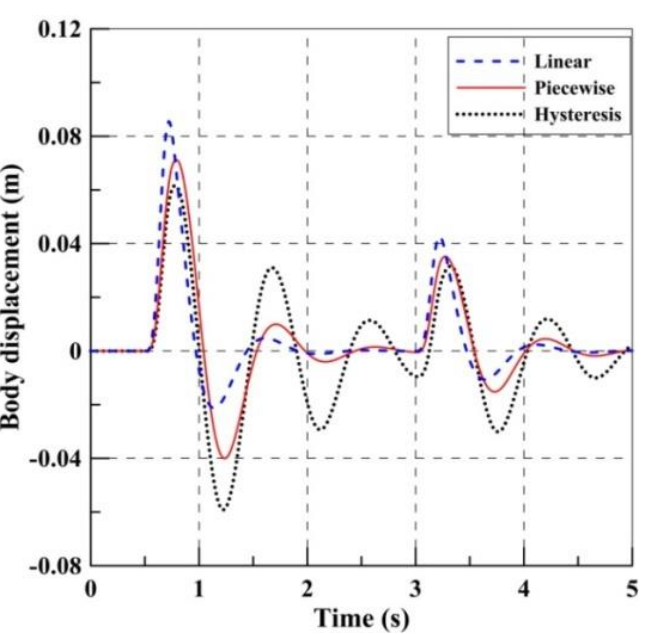

(b)

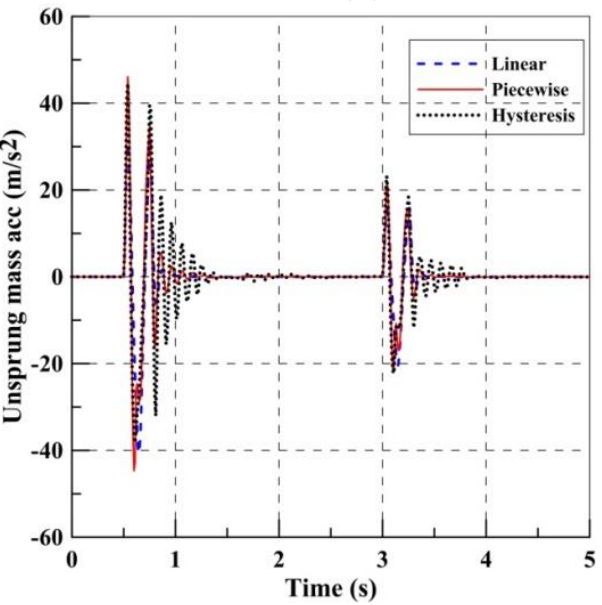

(d)

Figure 8. Simulation results for (a) body acceleration (b) body displacement (c) suspension deflection and (d) unsprung mass acceleration for linear and piecewise linear with hysteresis damping characteristic curve

It is well known that body acceleration and displacement are the most important criteria to decide the passenger comfort. From Figure 9(a), Figure 9(b) and Table 3, it can be seen that linear damping cannot be a choice to model the behaviour of shock absorber as the suspension responses predicted by such a model deviates significantly from the response generated from the experimentally obtained data. The linear model has body acceleration magnitude of approximately $10.5 \mathrm{~m} / \mathrm{s}^{2}$ whereas the other nonlinear models including piecewise have an acceleration magnitude of approximately (see Table 3) 6 $\mathrm{m} / \mathrm{s}^{2}$. The linear model has also predicted larger overshot as compared to other models. Although piecewise linear model shows better results compared to the linear model, its deviation from experimental data (hysteresis) is quite appreciable since the piecewise shock absorber model, which considers the compression and rebound behaviours and also low and high rod speeds, is accurate enough to obtain acceptable results (achieved 84\% RMS value of body acceleration of hysteresis model) than the complex hysteretic shock absorber model [8]. In fact, polynomial damping model captures the actual experimental data more closely than any other models. Another important factor affecting the body motion during road roughness is the settling time. Having a faster settling time improves 
comfort of passengers and ride quality [18]. Idea about the settling time can be obtained from the body displacement vs. time plot. It is apparent from Figure 9(b) that the settling time is quite large for experimental hysteresis data and polynomial damping model shows quite a similar trend in comparison. On the other hand, the linear and piecewise linear models predict that the settling time is lesser than the other model, which is a deviation from the actual cases.

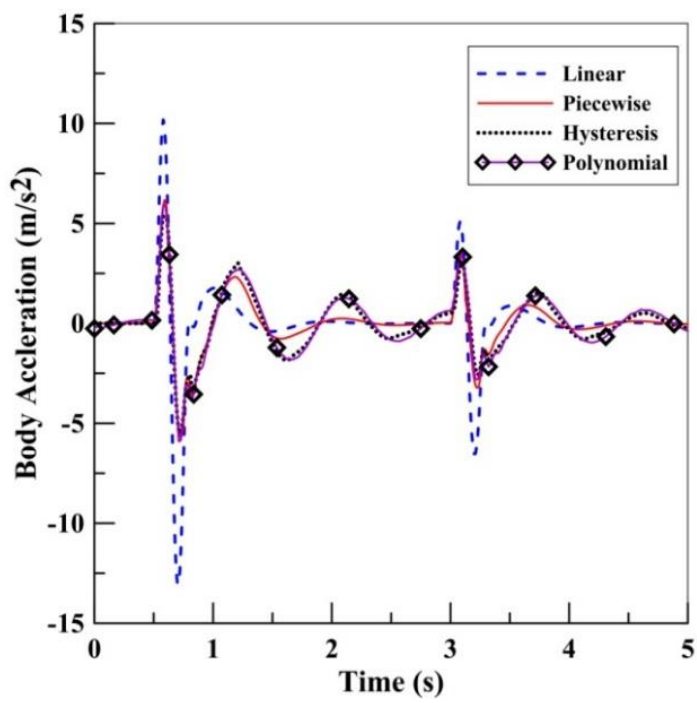

(a)

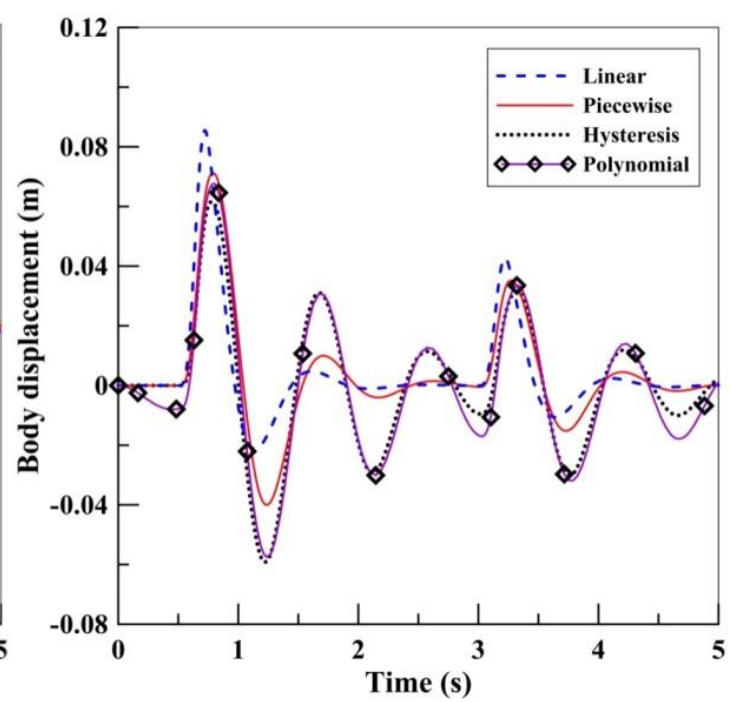

(b)

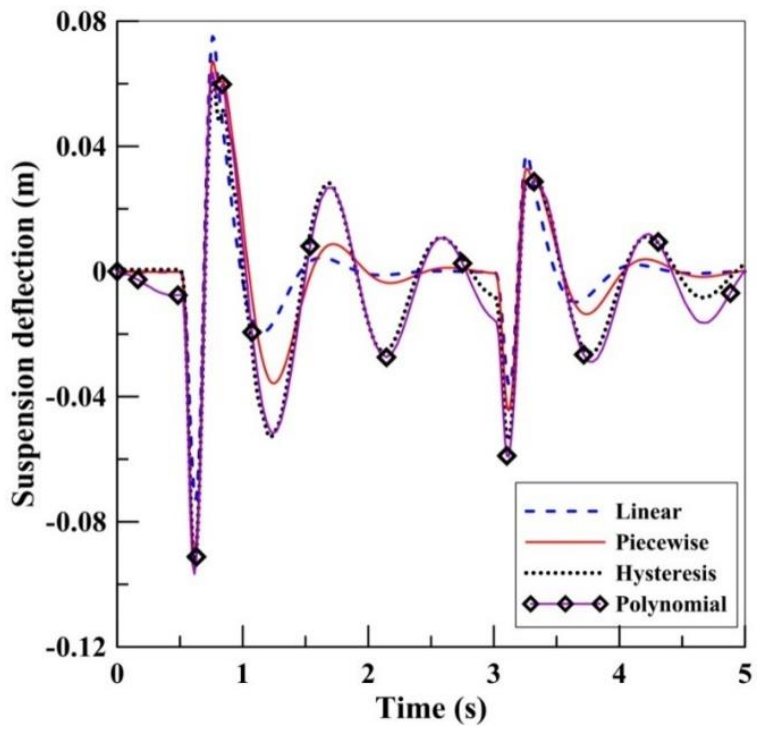

(c)

Figure 9. Comparative simulated results for (a) body acceleration using (b) body displacement (c) suspension deflection in time domain for linear, piecewise linear and polynomial with hysteresis damping characteristic curve.

\section{Frequency Domain Analysis}

The frequency response functions for the amplitude characteristics are generally used for assessment of dynamic systems in a frequency domain. These characteristics express the sensitivity of the dynamic system very well in response to the excitation having a variable 
frequency composition. To improve the ride quality, it is important to provide an effective isolation and reduce a resonance peak in sensitive frequency. The frequency analysis of sprung mass acceleration shows the effect of damping model on the behaviour of sprung mass because the sprung mass vibration isolation is the factor which determines the ride comfort [8]. In the present paper, frequency domain analysis of sprung mass acceleration and suspension deflection were carried out so that dynamic response due to road profile input can be identified more precisely.

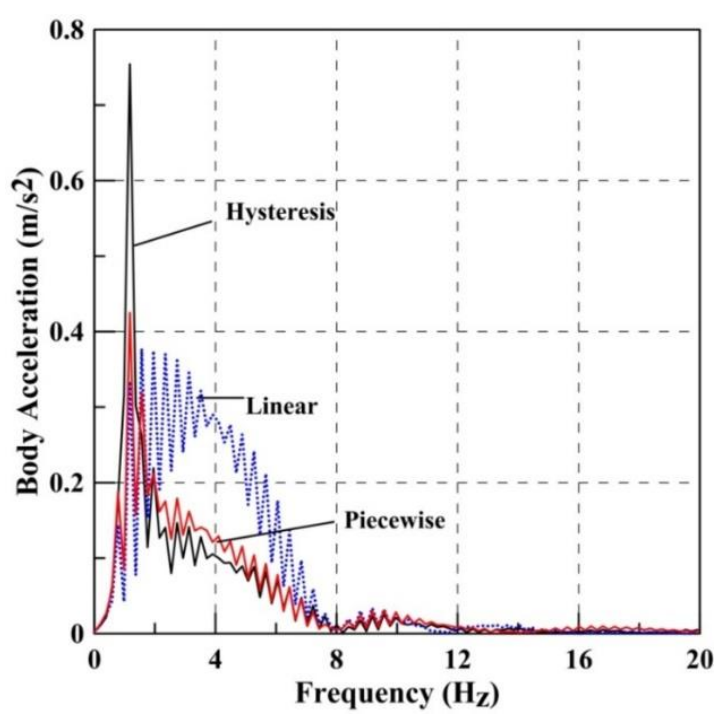

(a)

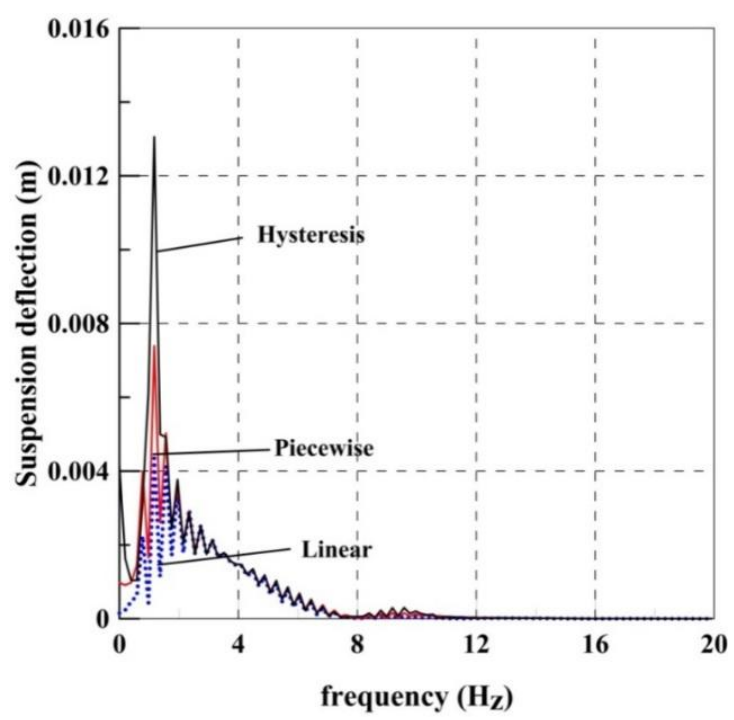

(b)

Figure 10. Simulation results for (a) body acceleration and (b) suspension deflection in frequency domain for linear and piecewise with hysteresis damping characteristic curve.

In many text books $[44,48]$, the fundamentals are included to study and design the vehicle dynamic. On the basis of the standard design of the vehicle, the sprung mass was chosen to have its natural frequency [44] at or just above $1 \mathrm{~Hz}$. Therefore, at frequencies near $1 \mathrm{~Hz}$ the sprung mass is resonating on the suspension and the road inputs are amplified. The natural frequency of sprung mass acceleration and unsprung mass acceleration are given by:

$$
\begin{gathered}
f_{n-\text { sprung }}=0.159 \sqrt{\frac{\left(k_{s} * k_{t} / k_{s}+k_{t}\right)}{m_{s}}} \\
f_{n-\text { unsprung }}=0.159 \sqrt{\frac{\left(k_{s}+k_{t}\right)}{m_{u s}}}
\end{gathered}
$$

Based on Eq. (12) and (13), the natural frequency of sprung mass was found to be $1.12 \mathrm{~Hz}$ and for unsprung mass it was $11.17 \mathrm{~Hz}$. In the natural frequency of unsprung mass the resonating effect in wheel hop resonance mode may be observed.

Figure 10(a) shows sprung mass or body acceleration against input frequency and the resonating effect at its natural frequency of around $1.12 \mathrm{~Hz}$ is exhibited. The amplitude ratio of this peak is very sensitive to damping level, and on typical passenger cars this ratio is in the range of 1.5 to 3.0 [44]. From Figure 10(a), it can be observed that at the resonant frequency, the acceleration has a sharp peak and it is surmised that if a damping coefficient is increased, the maximum amplitude of acceleration would decrease, 
providing better passenger comfort. However, at frequency range higher than resonance, with an increase in damping coefficient, isolation of the body from the road input becomes progressively worse. It highlights the fact that in order to have passenger comfort at resonant frequency, damping coefficient should be high as increase in damping coefficient decreases the response gain which in turn reduces sprung mass acceleration, thus, improving the ride quality of the vehicle. On the other hand, at frequencies higher than the natural frequency of the sprung mass, damping coefficient should be low for better isolation because at a frequency above the resonance, if damping coefficient suddenly decreases, it causes large body motion. Therefore, to accomplish better isolation in the resonance frequency, the damping coefficient has to be large, but at frequencies above the resonance, the damping coefficient has to be reduced [18]. It is also evident from the figure that curves for linear damping model and experimental data are quite far apart and do not match well. Hence, it can be said that linear model, which has a constant damping coefficient, fails to adequately capture the behaviour of the shock absorber. On the other hand, piecewise linear model has approximately 40 percent lower peak value than the experimental model at the resonant frequency and at a higher frequency range, the two curves show similar trends. The suspension spring is a critical element in establishing the passenger comfort because it is in series with the relatively stiff tire spring. Figure 10(b) shows the effect of external input frequency on suspension deflection. It is well established that the natural frequency is directly related to stiffness. Hence, it is always desirable to use high suspension spring stiffness to achieve better comfort or to reduce acceleration.

\section{CONCLUSIONS}

The effect of nonlinear shock absorber damping models on vehicle characteristics were analysed by using quarter car simulation using Simulink and Adams view. Based on the simulation results and quantitative analysis, it is evident that, the linear damping model shows higher peak amplitude for the body acceleration, larger overshoot displacement and higher suspension deflection values, whereas results of piecewise linear model also deviate from the polynomial results but quite acceptable as compared to the linear model. Regarding settling time, the linear and piecewise linear models show faster settling as compared to the polynomial model. From the frequency domain analysis, it was observed that the linear damping model is unable to capture nonlinearity of shock absorber whereas the piecewise linear model matches fairly well with the results of the experimental hysteresis curve. However, it is evident from the time domain analysis that out of the three proposed models, the polynomial damping model shows the best matching with realistic results obtained from the Adams view based on the experimental hysteresis curve. It can also be concluded from the analysis that the linear damping characteristics are inadequate to capture the realistic behaviour of the system. Hence, it is important that nonlinear damping characteristics should be included in the mathematical model and simulation of a shock absorber. Therefore, the proposed polynomial shock absorber model can be an enhancing choice for better prediction of vehicle dynamic responses.

\section{ACKNOWLEDGEMENTS}

The authors would like to thank to Jadavpur University, Kolkata for laboratory facilities. REFERENCES 
[1] Ikhsan N, Ramli R, Alias A. Analysis of kinematic and compliance of passive suspension system using Adams car. 2014.

[2] Nagarkar M, Vikhe G, Borole K, Nandedkar V. Active control of quarter-car suspension system using linear quadratic regulator. International Journal of Automotive and Mechanical Engineering. 2011;3:364-72.

[3] Sani M, Rahman M, Noor M, Kadirgama K, Rejab M. Study on dynamic characteristics of automotive shock absorber system. Malaysian Science and Technology Congress; MSTC08. 2008. p. 623-29.

[4] Pulvirenti G, Faria C. Influence of Housing Wall Compliance on Shock Absorbers in the Context of Vehicle Dynamics. IOP Conference Series: Materials Science and Engineering: IOP Publishing; 2017. p. 012026.

[5] Konieczny Ł. Analysis of simplifications applied in vibration damping modelling for a passive car shock absorber. Shock and Vibration. 2016;2016.

[6] Liu Y, Zhang J. Nonlinear dynamic responses of twin-tube hydraulic shock absorber. Mechanics Research Communications. 2002;29:359-65.

[7] Liu Y, Zhang J, Yu F, Li H. Test and simulation of nonlinear dynamic response for the twin-tube hydraulic shock absorber. SAE Technical Paper; 2002.

[8] Calvo J, Lopez-Boada B, Román JS, Gauchia A. Influence of a shock absorber model on vehicle dynamic simulation. Proceedings of the Institution of Mechanical Engineers, Part D: Journal of Automobile Engineering. 2009;223:189-203.

[9] Cui Y, Kurfess TR, Messman M. Testing and modeling of nonlinear properties of shock absorbers for vehicle dynamics studies. Proceedings of the World Congress on Engineering and Computer Science; 2010. p. 20-2.

[10] Lang H. Automotive dampers at high stroking frequency: Ph. D. Thesis, University of Michigan; 1977.

[11] Wallaschek J. Dynamics of non-linear automobile shock-absorbers. International Journal of Non-Linear Mechanics. 1990;25:299-308.

[12] Reybrouck K. A non linear parametric model of an automotive shock absorber. SAE Technical Paper; 1994.

[13] Duym S, Stiens R, Reybrouck K. Evaluation of shock absorber models. Vehicle System Dynamics. 1997;27:109-27.

[14] Spencer Jr B, Dyke S, Sain M, Carlson J. Phenomenological model for magnetorheological dampers. Journal of Engineering Mechanics. 1997;123:2308.

[15] Mollica R, Youcef-Toumi K. A nonlinear dynamic model of a monotube shock absorber. American Control Conference, 1997 Proceedings of the 1997: IEEE; 1997. p. 704-8.

[16] Chacón J, Boada B, Boada M, Díaz V. Experimental study and analytical model of bleed valve orifice influence of a high-performance shock absorber on vehicle dynamics. Advances in Mechanical Engineering. 2017;9:1687814017719004.

[17] Ryabov I, Novikov V, Pozdeev A. Efficiency of Shock Absorber in Vehicle Suspension. Procedia Engineering. 2016;150:354-62.

[18] Siradj R, Darsivan FJ, Hamid M, Abdullah MF. Nonlinear model identification of a shock absorber dynamics. Avtech 2013 Conference Proceedings: Eastern Mediteranean Academic Research Centre; 2013. p. 1-14.

[19] Li S, Lu Y, Li L. Dynamical test and modeling for hydraulic shock absorber on heavy vehicle under harmonic and random loadings. Research Journal of Applied Sciences, Engineering and Technology. 2012;4:1903-10. 
[20] Doria A, Lucchini M. An experimentally validated model of a motorcycle shock absorber for studying sus-pension dynamics. Proceedings of the ASME 2011 International Design Engineering Technical ConferencesComputers and Information in Engineering Conference Washington, DC, USA: ASME2011. p. 803-12.

[21] Cossalter V, Doria A, Pegoraro R, Trombetta L. On the non-linear behaviour of motorcycle shock absorbers. Proceedings of the Institution of Mechanical Engineers, Part D: Journal of Automobile Engineering. 2010;224:15-27.

[22] Kalyan Raj A, Padmanabhan C. A new passive non-linear damper for automobiles. Proceedings of the Institution of Mechanical Engineers, Part D: Journal of Automobile Engineering. 2009;223:1435-43.

[23] Popescu M-CO, Mastorakis NE. Testing and simulation of a motor vehicle suspension. International Journal of Systems Applications, Engineering \& Development, ISSN. 2009:2074-1308.

[24] Azraai M, Priyandoko G, Yusoff A, Rashid M. Parametric Optimization of magneto-rheological fluid damper using particle swarm optimization. International Journal of Automotive and Mechanical Engineering. 2015;11:25919.

[25] Mohd T, Hassan M, Aziz W. Mathematical modeling and simulation of an electric vehicle.

[26] Sandu C, Andersen ER, Southward S. Multibody dynamics modelling and system identification of a quarter-car test rig with McPherson strut suspension. Vehicle System Dynamics. 2011;49:153-79.

[27] Hurel J, Mandow A, García-Cerezo A. Kinematic and dynamic analysis of the McPherson suspension with a planar quarter-car model. Vehicle System Dynamics. 2013;51:1422-37.

[28] Kim C, Ro P, Kim H. Effect of the suspension structure on equivalent suspension parameters. Proceedings of the Institution of Mechanical Engineers, Part D: Journal of Automobile Engineering. 1999;213:457-70.

[29] Blundell $\mathrm{M}$. The influence of rubber bush compliance on vehicle suspension movement. Materials \& Design. 1998;19:29-37.

[30] Barber AJ. Accurate models for bushings and dampers using the empirical dynamics method. Proceedings of the International ADAMS Users' Conference, Mechanical Dynamics GmbH;1999.

[31] Maher D, Young P. An insight into linear quarter car model accuracy. Vehicle system dynamics. 2011;49:463-80.

[32] Agharkakli A, Sabet GS, Barouz A. Simulation and analysis of passive and active suspension system using quarter car model for different road profile. International Journal of Engineering Trends and Technology. 2012;3:636-44.

[33] Qazi AJ, Khan A, Khan MT, Noor S. A parametric study on performance of semiactive suspension system with variable damping coefficient limit. AASRI Procedia. 2013;4:154-9.

[34] Barethiye Vijay PGaMA. Simulation of quarter car model for the shock absorber compliance with rubber bush and washers. In: International Congress on Computational Mechanics and Simulation. Indian Institute of Technology, Bombay, Mumbai, Maharashtra; 2016.

[35] El-Kafafy M, El-Demerdash SM, Rabeih A-AM. Automotive ride comfort control using MR fluid damper. Engineering. 2012;4:179-87. 
[36] Kim C, Ro PI. An accurate full car ride model using model reducing techniques. Transactions-American Society of Mechanical Engineers Journal of Mechanical Design. 2002;124:697-705.

[37] Shirahatti A, Prasad P, Panzade P, Kulkarni M. Optimal design of passenger car suspension for ride and road holding. Journal of the Brazilian Society of Mechanical Sciences and Engineering. 2008;30:66-76.

[38] Darus R, Sam YM. Modeling and control active suspension system for a full car model. Signal Processing \& Its Applications, 2009 CSPA 2009 5th International Colloquium on: IEEE; 2009. p. 13-8.

[39] Raju AB, Venkatachalam R. Analysis of Vibrations of Automobile Suspension System Using Full-car Model. International Journal of Scientific \& Engineering Research. 2013;4:2105-11.

[40] Florin A, Ioan-Cozmin M-R, Liliana P. Passive suspension modeling using MATLAB, quarter-car model, input signal step type. New Technologies and Products in Machine Manufacturing Technologies. 2013:258-63.

[41] Cui Y, Kurfess TR. Vehicle parameter identification for vertical dynamics. Journal of Dynamic Systems, Measurement, and Control. 2015;137:021013.

[42] Mitra A, Benerjee N, Khalane H, Sonawane M, JoshI D, Bagul G. Simulation and Analysis of Full Car Model for various Road profile on a analytically validated MATLAB/SIMULINK model. IOSR J Mech Civ Eng IOSR-JMCE. 2013:22-33.

[43] Ahmad F, Mazlan S, Zamzuri H, Jamaluddin H, Hudha K, Short M. Modelling and validation of the vehicle longitudinal model. International Journal of Automotive and Mechanical Engineering. 2014;10:2042-56.

[44] Gillespie TD. Fundamentals of Vehicle Dynamics. Warrendale, PA: Society of Automotive Engineers. Inc; 1992.

[45] D'Amato FJ, Viassolo DE. Fuzzy control for active suspensions. Mechatronics. 2000;10:897-920.

[46] Sam Y, Hudha K. Modelling and Force Tracking Control of Hydraulic Actuator for an Active Suspension System. 2006 1ST IEEE Conference on Industrial Electronics and Applications.

[47] Conde EC, González FBnCAVb, Bracamontes RnCv. Generalized PI control of active vehicle suspension systems with MATLAB. Applications of MATLAB in Science and Engineering: InTech; 2011.

[48] Wong JY. Theory of ground vehicles: John Wiley \& Sons; 2008. 